\title{
A Quality Management-Based Approach to Evaluate Public Services: a case study in Brazil
}

\author{
Glauco V. Pedrosa and Vitor G. de Menezes and Rejane M. da C. Figueiredo \\ Information Technology Research and Application Center (ITRAC) \\ University of Brasilia (UnB/FGA), Brasilia, DF, Brazil \\ Email: \{glauco.pedrosa, rejane\}@unb.br, menezesvitorg@gmail.com
}

\begin{abstract}
In this paper, we present an approach to identify and measure the best practices of quality management in public services. While many studies focus on service quality from the user's perspective, this work pays attention to the service operation management, aiming to evaluate public services' best practices based on the management perspective. This study was developed in cooperation with the Brazilian Government, which conducted an exploratory interview with managers of 289 federal services. Then, we performed a data mining to better understand trends, patterns and correlations from the answers obtained. As a final outcome, a questionnaire-based model was developed, called BrQM (Brazil Quality Management), in order to assist public administration managers in evaluating the quality of their services. The proposed model encodes 8 dimensions with score variables to guide evaluation actions so that public institutions can improve their services by identifying good practices in quality management adopted by other services in the same sphere.
\end{abstract}

\section{Introduction}

Evaluating the quality of public services is a complex activity and requires a clear definition of its methodological assumptions. For a product, it is possible to establish clear standards of manufacture, operation, durability, absence of defects, etc. In this context, quality can be defined as the measurement of the product's conformity to these standards. On the other hand, evaluating the quality of a service is more associated with the value perceived by the user, which may include, for example, the infrastructure observed and the waiting time for the service $[1,2]$.

Service quality plays an important role in improving the provision of public services to citizens, whether digitized or not. In fact, better quality public services are supposed to lead to satisfied users, which will in turn increase trust in government [3]. Thus, the challenge is to develop instruments so that managers can improve their services according to the expectation of the citizens. However, the development of a service quality indicator should also take into consideration the management operations.

There is a difference between the perspective of the user and the perspective of the manager regarding the quality of the service. From the manager's point of view, quality refers to compliance, making sure the service operations conform to the management standards described by the strategic plan of the institution [4]. It is related to internal processes, which can represent the quality of the services provided by the institution, such as infrastructure, people management, simplification of procedures, among others.

In the case of public services, there is also demand for transparency, accountability and the quality assurance of institutions $[5,6]$. In this sense, the implementation of new strategies in the public sector is necessary to allow managers to evaluate actions and responses to ensure a high level quality of their services. Especially in the context of digital government transformation, the quality of the service depends heavily on the internal organization, such as the Information Technology (IT) infrastructure.

According to $[7,8,9]$, most public service quality assessment tools focus only on one aspect of government: the front-office processes. In general, internal processes and their impacts are ignored. Therefore, the authors point to the lack of a complete evaluation instrument that allow an effective management of the quality of public services.

This work examines which factors, in the view of managers, are more related to changes in quality levels, identifying dimensions and indices to measure the quality of service delivery, as well as to enable the comparison between different services offered to the same public.

This paper is structured as follows: section 2 presents a background with some definitions and the 
literature review. Section 3 presents the methodological steps applied to develop the model proposed in Section 4. In Section 5, we present the model as it is applied to evaluate Brazilian public services. In Section 6, we make final considerations.

\section{Background}

\subsection{Service quality}

The construction and implementation of new strategies for public services require instruments to evaluate their success. Service evaluation is different from product evaluation. A product is something tangible and therefore can have its quality measured with objective criteria, such as functioning, appearance and durability. Services are intangible and heterogeneous, which makes their evaluation more complex. In a service, quality is usually measured on the basis of performance and the user's experience $[1,2,10]$.

According to [11], the quality of a service can be defined as the extent to which service delivery meets user expectations. In the same sense, [12] argue that the customer's perspective is essential to measure their satisfaction with the service. Therefore, evaluating services from a user perspective is critical to measuring success, identifying deficient points in the delivery process, as well as constructing and planning actions to improve these aspects. Thus, perceived quality has become an important metric for the evaluation of services.

The initial models of service evaluation were generally focused on retail organizational contexts, seeking to understand all the aspects that influenced the perspective of the users about each type of service [1,2]. Subsequently, the development of new technologies and the digitization of services led to the emergence of new configurations and contexts. Responding to these changes, new models, adapted to the contexts where service delivery has an online phase, have emerged $[13,14]$. The E-S-QUAL [15] model also arises in this regard to assess the quality delivered by websites where customers make their purchases and, despite its focus on websites, seeks to encompass phases after interaction with the service, such as fullfillment and returns.

\subsection{Public service quality evaluation}

Several governments have developed tools to assess, monitor and improve the quality of their services, such as the American Customer Satisfaction Index (ACSI) and the European Customer Satisfaction Index (ECSI) [16]. This is important because research has shown that, in general, the existing measures are too generic, ignoring the social, cultural and environmental specificities of different countries [17].

To evaluate government services, especially e-services, several studies have attempted to incorporate tools used in the private sector. Srivastava et al. [18], for example, apply the SERVQUAL gap model to study their relationship to user satisfaction in the e-government context of Singapore. Other models are adaptations based on the model DeLone\&McLean $[19,20]$, or the Technology Acceptance Model (TAM) $[6,21]$.

Extensions of private sector models arise, such as the E-PS-QUAL model [22], based on the E-S-QUAL model but for public sector application. The authors of the model point out how the loyalty factor, which is essential in the commercial sector, generally does not have the same meaning in the public sector, and how the concept of perceived value differs in each field. Changes are also made such as the removal of the Fulfillment dimension, argued as irrelevant to the context of a tax filling website, which may not be the case for other types of public services.

New models also emerge, such as the E-government Citizen Satisfaction Framework (ECSF) [17] and the e-SQUUX [23], proposing dimensions that can be adapted and selected according to the context. Recent studies also have pointed out the need to highlight the specificity of the evaluation context in public services vis-à-vis the private sector, since government agencies often have a monopoly on service delivery, which could make evaluation on the basis of user satisfaction inefficient. They suggest, therefore, the search for measures that analyze this particularity [8].

\subsection{The manager's perspective of service quality}

Quality management is an area with few instruments to support decision-making, especially in the field of management linked to information systems [9]. According to [4], the employee's knowledge of tasks to be performed by the user as well as their dedication are important factors for the quality of the services. Therefore, the knowledge and perception of employees, especially of managers, is essential for effective quality management.

A quality management based approach widely used in the past is Total Quality Management (TQM), adopted both in the private sector [24] and in the public sector [25]. Although there is no consensus on its concept and activities [26, 24], authors and organizations propose definitions for it. Al-Damen [26], for example, defines TQM as a management 
culture adopted by the organization in order to maximize customer satisfaction.

Some authors, such as [27], incorporate TQM into other approaches, which brings the SERVQUAL gap structure to TQM linked to an analysis of critical success factors, proposing a management approach as well as a quality assessment. In addition, ISO 9000 presents a series of internationally accepted guidelines similar to those of TQM for the definition and adoption of quality management systems [28].

Other approaches for evaluating services from the managers' point of view also appear, such as adaptations of lean [29, 30], bringing new dimensions to evaluation and management and contextualizing lean optimization concepts into, for example, information systems.

2.3.1. The manager's perspective of service quality in the public sector The quality of public services from the perspective of managers is linked to the concept of public value. Public value refers to the value generated by a government for its citizens. Therefore, public managers must actively create public value, meeting the individual and collective desires of citizens, working to improve the quality of services delivered, reducing costs and enhancing the fairness of operations. It should also be noted that the concept of public value is neither universal nor constant over time, so public managers must be aware of changes in the needs and preferences of the public [31, 32, 33].

Furthermore, the implementation of new public service strategies, such as the increasing adoption of digital governance practices, foresees the construction of new instruments and tools that allow managers to evaluate actions and responses to the level of quality of their services. Especially in a context of government transformation, service quality depends heavily on the internal organization [7].

According to [7, 8, 9], most evaluation tools focus only on one aspect of government, measuring the quality of front-office processes and service delivery to the user. In general, internal processes and their impacts are ignored. Therefore, the authors point to the lack of a complete instrument of evaluation of public services that allow an effective management of its quality.

\section{Research Methodology}

The main purpose of this work is to understand the perspective of service managers towards service quality. To do so, the methodology adopted was a quantitative descriptive research followed by a statistical and semantic analysis.
This study has two parts: the first one was carried out by the Brazilian government with the managers of Brazilian public services, and the second one corresponds to our data mining, using a multivariate exploratory data analysis.

As a final result, we present a questionnaire based model with indicator scores. This model, called Brazil Quality Management (BrQM), supports managers of public services by mapping dimensions and indicators with which they can get to know, analyze and improve their services, as well as compare their strategies with those of other public institutions. This comparison can be made with the final score obtained after the evaluation model is applied.

\subsection{Preliminary Information}

The set of variables (questions) and the guiding dimensions were developed by the Department of Service Modernization and Innovation (INOVA) of the Brazilian Ministry of Planning, Development and Management.

The set of questions adopted by INOVA was derived from the Inter-American Development Bank (IDB) Service Evaluation Model, called Simplifying Lives (SV) [34], which was developed especially for the Latin American public sector. The SV model was properly validated and pre-tested in six countries: Chile, Ecuador, Panama, Paraguay, Trinidad and Tobago, and Uruguay. It should be noted that the set of countries seeks to be a representative sample of the diversity of situations (institutional, social and economic) found in Latin America.

\subsection{Data Collection}

Data was gathered by means of in-depth interviews with the managers of 289 public services of the Brazilian government. These interviews were conducted by the INOVA Departament of Brazilian Governement. The interviews took place between September, 18 and October 26, 2018.

The interview was structured as a questionnaire that covered aspects of public services related to: Process, User Relationship, Management and Regulation, Resources and Digital Government, derived from the $\mathrm{SV}$ model discussed in previous section. Considering these dimensions, a preliminary questionnaire was applied and further refined from a test conducted between September 3 and September 12, 2018 with public service managers from 9 federal institutions, which refers to $5 \%$ of the expected number of responses. Comments and suggestions for improvement were received and incorporated in the final version. 
The final questionnaire, properly validated and pre-tested, is presented in Table 1. Each manager was asked to respond objectively to each of the issues presented in the questionnaire. Some questions were binary (yes-no answers) and some followed a Likert-4 scale, in which 0 - Strongly Disagree; 1 - Disagree; 3 Agree; and 4 - Strongly Agree.

Table 1. Questionnaire answered by managers of Brazilian public services
ID

Question Are there any measurements of the user's waiting time until service delivery? (Delivery: final administrative act in the provision of the service)

2 How many days does the user wait until the service is delivered?

3 How many areas of the institution are involved in providing the service? (Area: sector that represents the lowest hierarchical level in the organizational chart of the institution)

4 In average, how often does the user interact with the institution until the delivery of the service? (Interaction: every time a user interacts with the institution during the service delivery)

5 How many documents does the user need to present to the service?

How can the users register their complaint or suggestion?

6 In Person (Ombudsman's Office)

7 Face-to-face (another service area)

8 Telephone (call center)

9 Service Website

10 Institution's own portal

11 Ombudsman (e-Ouv)

12 Chat or Chatbot

13 Mobile app

14 Evaluation on a form on paper

15 Does your institution use complaint data and suggestions for service improvement?

16 Is there a total cost measurement for the user?

17 Is there a tool for the user to evaluate their satisfaction with the service?

18 Are users involved in service Yes/No improvement processes?

19 The institution is proactive in providing information of interest to users about the services

20 The documentary requirements for the provision of the service could be reduced.

21 The institution has channels for the dissemination of information on service performance and improvement actions.

Yes/No

Yes/No

Yes/No

Yes/No

Yes/No

Yes/No

Yes/No

Yes/No

Yes/No

Yes/No

Yes/No

Yes/No

Likert 4

Likert 4

Likert 4
Expected

Response

22 Is the service included in the strategic plan of the institution? management model defined for the provision of the service?

24 Does the institution have a regular process of evaluating the quality of the service provided?

25 Are there people specifically dedicated to quality assessment?

26 Top management evaluates the coherence between the mission of the institution and the services it offers.

27 Top management monitors the quality standards of the services provided.

28 Top management sponsors the disclosure of the services in the Services' Website.

29 Top management promotes improvements in management processes, with the aim of reducing the requirements for service users.

Open-Ended

Response

Open-Ended

Response

Open-Ended

Response

30 Are there alliances, partnerships, initiatives for collaboration and / or integration with other public institutions that aim to improve the service?

31 Are there training actions associated with the analyzed service (consider only the training linked to the analyzed service, not the institution as a whole)?

32 Are the incentives offered to employees for their performance associated with improved service quality?

33 The institution promotes the transfer of knowledge among employees.

34 There is a training policy for all employees.

35 The current number of employees is adequate to provide the service.

36 Employees are trained to provide the service as soon as they start their activities.

37 Employees are selected according to the skills required to provide the service.

Which of the following actions can be carried out by the user via the internet?

38 Accessing information about the Yes/No documents needed to request the service

39 Acessing step-by-step information on Yes/No how to order the service

40 Performing scheduling

Yes/No

41 Consulting scheduling already done Yes/No

42 Requesting the service Yes/No

43 Following the service Yes/No

44 Recording suggestion or complaint Yes/No

45 Receiving the response or solution to a Yes/No request, suggestion or complaint
23 Does the institution follow a quality Yes/No

Response 
48 Systems are reliable in terms of Likert 4 availability

49 Systems make day-to-day management of the service easier

50 Systems provide reliable data and Likert 4 information

51 Existing systems ensure complete Likert 4 support for the service provided

52 The systems provide the services' data in Likert 4 the open format

53 Systems meet accessibility requirements Likert 4

54 Regular strategies for service Likert 4 dissemination to the user are effective.

\subsection{Exploratory Factor Analysis}

Factor analysis is a statistical method used to describe variability among correlated variables in terms of a potentially lower number of unobserved variables called factors. Our goal when applying the Factorial Analysis is to reduce the variables by grouping them into a smaller number of correlated factors. In this way, it is possible to analyse the data as a smaller number of dimensions will be obtained from the initial number of variables.

3.3.1. Statistical Validation In order to verify if factorial analysis was a suitable method for the purposes of this study, two statistical tests were used:

- Kaiser-Meyer-Oklin (KMO): this test is a measure of how suited the data is for Factor Analysis. The test measures sampling adequacy for each variable in the model and for the complete model. The statistic is a measure of the proportion of variance among variables that might be common variance. High values (close to 1.0) generally indicate that a factor analysis may be useful with the data. If the value is less than 0.50 , the results of the factor analysis probably won't be very useful.

- Bartlett's Sphericity tests the hypothesis that the correlation matrix is an identity matrix, which would indicate that your variables are unrelated and therefore unsuitable for structure detection. Small values (less than 0.05) of the significance level indicate that a factor analysis may be useful with the analyzing data.

Analyzing the results of the statistical tests of the applied questionnaire, it is observed that the results of factorability of correlation matrix were adequate: KMO $=0.751$; Bartlett's Test of Sphericity was statistically significant, $\chi^{2}=5552.42$, and $\mathrm{p}<0.01$. Therefore, it is concluded that the results are acceptable for the evaluation of the reliability of the applied questionnaire.

3.3.2. Total variance matrix explained The variance matrix indicates the total percentage of variance that is explained by the factors obtained. The factors must present accumulated variance of at least $60 \%$, that is, the accumulated percentage presenting a value equal to or greater than $60 \%$ determines the number of factors extracted.

Table 2 shows that a $60.22 \%$ explained variance is reached when 15 factors are extracted.

Table 2. Variance of each component in the factorial analysis

\begin{tabular}{|l|l|l|}
\hline Components & \% of variance & \% cumulative \\
\hline 1 & 7.288 & 7.288 \\
\hline 2 & 6.281 & 13.569 \\
\hline 3 & 5.218 & 18.788 \\
\hline 4 & 4.176 & 22.964 \\
\hline 5 & 4.152 & 27.116 \\
\hline 6 & 4.023 & 31.139 \\
\hline 7 & 3.621 & 34.76 \\
\hline 8 & 3.538 & 38.299 \\
\hline 9 & 3.424 & 41.722 \\
\hline 10 & 3.367 & 45.089 \\
\hline 11 & 3.363 & 48.452 \\
\hline 12 & 3.344 & 51.796 \\
\hline 13 & 3.068 & 54.864 \\
\hline 14 & 2.696 & 57.561 \\
\hline 15 & 2.668 & 60.229 \\
\hline
\end{tabular}

\subsubsection{Component Matrix and Factor Loading} The Component Matrix shows which variables belong to each factor along with the factorial load explained by each variable in that factor. Table 4 in the Appendix section shows the 15 factors, together with the factor loads explained by each variable in each component. The variables with a factorial load greater than 0.4 in absolute value were highlighted. Studies indicate that variables with factor loads greater than 0.4 (in absolute value) explain better the variance in each component. For this reason, we used this strategy.

If the threshold of 0.4 is adopted, some variables could not contribute with enough factorial load in any component, such as "people dedicated to quality assessment", "total cost to the user", "use of chat or chatbot or mobile app as complaint channels". In 




Figure 1. Evaluation of Brazilian public services using the proposed model.

fact, these variables did not present much variation in the responses, so their factorial loads did not reach a factorial load statistically above 0.4 in any component.

\section{Method proposed to measure quality management in public sectors: BrQM}

The factorial analysis performed yielded the development of a model to compare the management best practices of Federal Public Administration activities. Also, it helped to define weights associated with each indicator and eventually create a final indicator to measure the "management quality".

Table 3 shows the final structure of the model used to evaluate service quality. This model is a questionnaire encoding 8 dimensions. These 8 dimensions were defined by grouping some factors which presented similar semantic correlation.

The weights of each variable were defined in relation to their factorial load and the weights of each dimension in relation to the variance explained by each dimension in the exploratory factorial analysis. For this reason, some dimensions have greater weight than others, as some dimensions include more factorial components in their construction. For example, the dimension "Satisfaction Evaluation" has a greater weight than the other dimensions, since it includes 3 factorial components.

The answers expected for each question are also specified in Table 3. Yes/no questions assume the following values: 0 (No) and 1 (Yes). The Likert 4 responses refer to scales of agreement using the following values: 0 - I totally disagree, 0.33 - Partially
Disagree, 0.66 - Partially Agree, and 1 - Totally Agree. For this type of response, the higher the level of agreement, the greater the final weight in the evaluation.

Only three questions have open answers: 1) How many documents does the user need to present to the service? 2) How many areas of the institution are involved in providing the service? 3) How often does the user interact with the institution until service delivery? The expected answers for these three questions were defined within the range 0 to 5 , which was the variation of the answers obtained in the research. To evaluate these questions, the lower the value assigned to the response, the greater the weight, that is, considering the interval 0 to 5 , the following weights are given: $0=1,2$ $=0.8,3=0.6,4=0.4$ and $5=0$.

\section{Evaluating the Quality Management of Brazilian Services}

Based on the instrument proposed in the previous section, sample data were analyzed in order to build up the profile of the services in relation to the dimensions proposed. The aim was to compare the management policies adopted by public institutions that participated in the research.

Figure 1 shows the results according to the best service evaluated (blue), the worst service evaluated (red), and the average score obtained from the evaluated services (green). It is noted that the Documentary Requirements and Attendance is the dimension with the lowest evaluation in the average of evaluated services, around $46 \%$. On the other hand, the dimensions Management and Systems have the means with better 
Table 3. The proposed questionnaire-based model to measure the quality management of public services

\begin{tabular}{|c|c|c|c|c|}
\hline Dimensions & Weight & Variables & Weight & $\begin{array}{l}\text { Answer } \\
\text { Type }\end{array}$ \\
\hline \multirow{6}{*}{ Systems } & \multirow{6}{*}{0.12} & Systems provide reliable data and information & 0.2 & Likert 4 \\
\hline & & Systems make day-to-day management of the service easier & 0.19 & Likert 4 \\
\hline & & Existing systems ensure complete support for the service provided & 0.18 & Likert 4 \\
\hline & & Systems are reliable in terms of availability & 0.17 & Likert 4 \\
\hline & & Systems meet accessibility requirements & 0.15 & Likert 4 \\
\hline & & The systems provide the data of the services in the open format & 0.11 & Likert 4 \\
\hline \multirow{4}{*}{ Governance } & \multirow{4}{*}{0.1} & $\begin{array}{l}\text { Top management evaluates the coherence between the mission of the } \\
\text { institution and the services it offers. }\end{array}$ & 0.27 & Likert 4 \\
\hline & & $\begin{array}{l}\text { Top management promotes improvements in management processes, with } \\
\text { the aim of reducing the requirements for service users. }\end{array}$ & 0.27 & Likert 4 \\
\hline & & Top management monitors the quality standards of the services provided. & 0.25 & Likert 4 \\
\hline & & $\begin{array}{l}\text { Top management sponsors the disclosure of the services in the Services } \\
\text { Portal. }\end{array}$ & 0.21 & Likert 4 \\
\hline \multirow{5}{*}{$\begin{array}{l}\text { Human } \\
\text { Resources }\end{array}$} & \multirow{5}{*}{0.09} & $\begin{array}{l}\text { Employees are trained to provide the service as soon as they start their } \\
\text { activities. }\end{array}$ & 0.26 & Likert 4 \\
\hline & & The institution promotes the transfer of knowledge among employees. & 0.2 & Likert 4 \\
\hline & & There is a training policy for all employees. & 0.18 & Likert 4 \\
\hline & & Employees are selected from the skills required to provide the service. & 0.18 & Likert 4 \\
\hline & & The current number of employees is adequate to provide the service. & 0.18 & Likert 4 \\
\hline \multirow{5}{*}{$\begin{array}{l}\text { Digital } \\
\text { Resources }\end{array}$} & \multirow{5}{*}{0.15} & $\begin{array}{l}\text { Actions that can be carried out via the internet: Step-by-step information } \\
\text { on how to order the service }\end{array}$ & 0.2 & Yes/No \\
\hline & & $\begin{array}{l}\text { Actions that can be carried out via the internet: Information about } \\
\text { documents needed to request the service }\end{array}$ & 0.19 & Yes/No \\
\hline & & Actions that can be carried out via the internet: Follow the service & 0.15 & Yes/No \\
\hline & & $\begin{array}{l}\text { Actions that can be carried out via the internet: Consult scheduling already } \\
\text { done }\end{array}$ & 0.23 & Yes/No \\
\hline & & Actions that can be carried out via the internet: Perform scheduling & 0.23 & Yes/No \\
\hline \multirow{8}{*}{$\begin{array}{l}\text { Satisfaction } \\
\text { Evaluation }\end{array}$} & \multirow{8}{*}{0.19} & $\begin{array}{l}\text { Is there a tool for the user to evaluate their satisfaction with the service } \\
\text { received? }\end{array}$ & 0.15 & Yes/No \\
\hline & & $\begin{array}{l}\text { Does the institution have a regular process of evaluating the quality of the } \\
\text { service provided? }\end{array}$ & 0.14 & Yes/No \\
\hline & & Are there measurements of the user's waiting time until service delivery? & 0.09 & Yes/No \\
\hline & & Regular strategies for service dissemination to the user are effective. & 0.12 & Likert 4 \\
\hline & & Are users involved in service improvement processes? & 0.12 & Yes/No \\
\hline & & $\begin{array}{l}\text { The institution is proactive in providing information of interest to users } \\
\text { about the services }\end{array}$ & 0.09 & Likert 4 \\
\hline & & $\begin{array}{l}\text { Actions that can be carried out via the internet: Record suggestion / } \\
\text { complaint }\end{array}$ & 0.16 & Yes/No \\
\hline & & $\begin{array}{l}\text { Actions that can be carried out via the internet: Receive response or solution } \\
\text { to a request, suggestion / complaint }\end{array}$ & 0.14 & Yes/No \\
\hline \multirow{5}{*}{$\begin{array}{l}\text { Documentary } \\
\text { requirements } \\
\text { and } \\
\text { Assistance }\end{array}$} & \multirow{5}{*}{0.11} & $\begin{array}{l}\text { The documentary requirements necessary for the provision of the service } \\
\text { could be reduced. }\end{array}$ & 0.24 & Likert 4 \\
\hline & & How many documents does the user need to present for the service? & 0.2 & $0,1,2,3,4,5$ \\
\hline & & Actions that can be carried out via the internet: Make payment & 0.17 & Yes/No \\
\hline & & How many areas of the institution are involved in providing the service? & 0.25 & $0,1,2,3,4,5$ \\
\hline & & $\begin{array}{l}\text { In an estimated way, how often does the user interact with the institution } \\
\text { until the delivery of the service? }\end{array}$ & 0.15 & $0,1,2,3,4,5$ \\
\hline
\end{tabular}




\begin{tabular}{|c|c|c|c|c|}
\hline Dimensions & Weight & Variables & Weight & $\begin{array}{l}\text { Answer } \\
\text { Type }\end{array}$ \\
\hline \multirow{5}{*}{$\begin{array}{l}\text { Service } \\
\text { Channels } \\
\text { (for } \\
\text { complaints } \\
\text { or } \\
\text { suggestions) }\end{array}$} & \multirow{5}{*}{0.1} & In Person (Ombudsman's Office) & 0.27 & Yes/No \\
\hline & & Service Website & 0.18 & Yes/No \\
\hline & & Face-to-face (another service area) & 0.15 & Yes/No \\
\hline & & Ombudsman (e-Ouv) & 0.26 & Yes/No \\
\hline & & Telephone (call center) & 0.14 & Yes/No \\
\hline \multirow{5}{*}{$\begin{array}{l}\text { Strategies } \\
\text { and } \\
\text { Transparency }\end{array}$} & \multirow{5}{*}{0.14} & $\begin{array}{l}\text { Are there alliances, partnerships, initiatives for collaboration and / or } \\
\text { integration with other public institutions that aim to improve the service } \\
\text { provided? }\end{array}$ & 0.24 & Yes/No \\
\hline & & $\begin{array}{l}\text { The institution has channels for the dissemination of information on service } \\
\text { performance and improvement actions. }\end{array}$ & 0.13 & Likert 4 \\
\hline & & Channel for complaints/suggestions: Evaluation on a form on paper & 0.22 & Yes/No \\
\hline & & $\begin{array}{l}\text { Are incentives offered to employees for their performance associated with } \\
\text { improved service quality? }\end{array}$ & 0.18 & Yes/No \\
\hline & & Is the service included in the strategic plan of the institution? & 0.23 & Yes/No \\
\hline
\end{tabular}

evaluations.

Regarding the final index, which takes into account the weights of each dimension and each variable, the best service evaluated got a grade of 9,045 , while the worst service got a grade of 1,654 , considering the range of 0 to 10 . No evaluated service reached the maximum of 10 points. The overall mean of the services evaluated was 5.45. The worst performers were Documentary Requirements and Attendance, and Strategies and Transparency.

\section{Conclusion}

This paper presented an evaluation model, BrQM, composed by indexes and variables that allow managers to know, analyze and improve the services offered. Also, it compares their strategies with those of other public institutions.

BrQM represents a benchmark to evaluate the quality of government services based on the managers' perspective. It avoids the tendency to apply private sector practices directly to the public sector. Although private and public sectors can (and should) exchange good practices, both sectors should observe the peculiarities of their relations with the user. BrQM can be used by public institutions of any level of the federation, for any service.

This paper presented the development of a comparative index of quality management for organizations in Federal Public Administration. The intention was to provide managers with information regarding the strengths and weaknesses of their management when compared to the strategies used by other institutions.

The model proposed was applied to evaluate the quality management of Brazilian public services. The results show that transparency and bureaucracy are two aspects that hinder the quality evaluation of Brazilian public services.

Nevertheless, it is important to consider the exploratory nature of this study and the proposed instrument. More data must be collected to improve the instruments and "train" the model. It is necessary to verify the behavior of the instruments when dealing with a greater mass of data, coming from their application in the public sphere.

\section{Acknowledgments}

This research is part of a cooperation agreement between the Information Technology Research and Application Center (ITRAC) and the Brazilian Minister of Economy.

\section{References}

[1] A. Parasuraman, V. A. Zeithaml, and L. L. Berry, "A Conceptual Model of Service Quality and Its Implications for Future Research," Journal of Marketing, vol. 49 , no. 4 , p. $41,1985$.

[2] A. Parasuraman, V. A. Zeithaml, and L. L. Berry, "SERVQUAL: A Multiple-Item Scale for Measuring Consumer Perceptions of Service Quality," p. 30, 1988.

[3] S. Bouckaert, G. Van de Walle, "Quality of public service delivery and trust in government. in: Governing networks," EGPA Yearbook, pp. 299-318, 2003.

[4] Hsieh, Rai, Petter, and Zhang, "Impact of User Satisfaction with Mandated CRM Use on Employee 
Service Quality," MIS Quarterly, vol. 36, no. 4, p. 1065, 2012.

[5] M. A. Alanezi, A. K. Mahmood, and S. Basri, "Conceptual model for measuring e-government service quality," in 2011 IEEE Conference on Open Systems, (Langkawi, Malaysia), pp. 411-416, IEEE, 2011.

[6] D. Bhattacharya, U. Gulla, and M. Gupta, "E-service quality model for Indian government portals: Citizens' perspective," Journal of Enterprise Information Management, vol. 25, no. 3, pp. 246-271, 2012.

[7] M. Kunstelj and M. Vintar, "Evaluating the progress of e-government development: A critical analysis," Information Polity, vol. 9, pp. 131-148, May 2005.

[8] J. Langham, N. Paulsen, and C. Hartel, "Evaluating Design Effectiveness for Public Sector Services: An Introduction to XE," p. 8, 2017.

[9] M. I. Arias and A. C. G. Maçada, "Digital Government for E-Government Service Quality: A Literature Review," in Proceedings of the 11th International Conference on Theory and Practice of Electronic Governance - ICEGOV'18, (Galway, Ireland), pp. 7-17, ACM Press, 2018.

[10] M. Gupta and D. Jana, "E-government evaluation: A framework and case study," Government Information Quarterly, vol. 20, pp. 365-387, Jan. 2003.

[11] N. M. Hien, "A Study on Evaluation of E-Government Service Quality," vol. 8, no. 1, p. 4, 2014.

[12] F. Sá, A. Rocha, and M. Pérez Cota, "From the quality of traditional services to the quality of local e-Government online services: A literature review," Government Information Quarterly, vol. 33, pp. 149-160, Jan. 2016.

[13] F. D. Davis, R. P. Bagozzi, and P. R. Warshaw, "User Acceptance of Computer Technology: A Comparison of Two Theoretical Models," Management Science, vol. 35, pp. 982-1003, Aug. 1989.

[14] W. H. DeLone and E. R. McLean, "The DeLone and McLean Model of Information Systems Success: A Ten-Year Update," Journal of Management Information Systems, vol. 19, no. 4, pp. 9-30, 2003.

[15] A. Parasuraman, V. A. Zeithaml, and A. Malhotra, "E-S-QUAL: A Multiple-Item Scale for Assessing Electronic Service Quality," Journal of Service Research, vol. 7, pp. 213-233, Feb. 2005.

[16] F. Zheng and Y. Lu, "Influencing Factors of Public Satisfaction in Local Governments' Overall Performance Evaluation in China," in 2012 Fifth International Conference on Business Intelligence and Financial Engineering, (Lanzhou, Gansu, China), pp. 495-500, IEEE, 2012.

[17] A. Sigwejo and S. Pather, "A Citizen-Centric Framework For Assessing E-Government Effectiveness," The Electronic Journal of Information Systems in Developing Countries, vol. 74, no. 1, pp. 1-27, 2016.

[18] S. Srivastava, T. Teo, and R. Nishant, "What is Electronic Service Quality?," p. 14, 2011.

[19] Y.-S. Wang and Y.-W. Liao, "Assessing eGovernment systems success: A validation of the DeLone and McLean model of information systems success," Government Information Quarterly, vol. 25, no. 4, pp. 717-733, 2008.

[20] J. Floropoulos, C. Spathis, D. Halvatzis, and M. Tsipouridou, "Measuring the success of the Greek Taxation Information System," International Journal of Information Management, vol. 30, no. 1, pp. 47-56, 2010 .
[21] S. Alotaibi and D. D. Roussinov, "User acceptance of m-government services in Saudi Arabia : An SEM approach," 2017.

[22] R. Connolly, F. Bannister, and A. Kearney, "Government website service quality: A study of the Irish revenue online service," European Journal of Information Systems, vol. 19, pp. 649-667, Dec. 2010.

[23] S. Ssemugabi and M. R. de Villiers, "Make Your Choice: Dimensionality of an Open Integrated Conceptual Model for Evaluating E-Service Quality, Usability and User Experience (e-SQUUX) of Web-Based Applications," in Proceedings of the Annual Conference of the South African Institute of Computer Scientists and Information Technologists on - SAICSIT '16, (Johannesburg, South Africa), pp. 1-10, ACM Press, 2016.

[24] A. Islam and A. F. M. A. Haque, "Pillars of TQM Implementation in Manufacturing Organization- An Empirical Study," p. 14, 2012.

[25] United States of America. Department of Defense., "Total Quality Management Master Plan," 1988.

[26] D. R. A. Al-Damen, "The impact of Total Quality Management on organizational performance Case of Jordan Oil Petroleum Company," vol. 8, no. 1, p. 11, 2017.

[27] A. Calabrese and F. Scoglio, "Reframing the past: A new approach in service quality assessment," Total Quality Management \& Business Excellence, vol. 23, pp. 1329-1343, Dec. 2012.

[28] C. Kartha, "A comparison of ISO 9000:2000 quality system standards, QS9000, ISO/TS 16949 and Baldrige criteria," The TQM Magazine, vol. 16, pp. 331-340, Oct. 2004.

[29] P. Punnakitikashem, "Determining Lean Practices in Health Care Service Systems," in The 19th International Conference on Industrial Engineering and Engineering Management (E. Qi, J. Shen, and R. Dou, eds.), pp. 945-954, Berlin, Heidelberg: Springer Berlin Heidelberg, 2013.

[30] U. M. Apte and C.-H. Goh, "Applying lean manufacturing principles to information intensive services," International Journal of Services Technology and Management, vol. 5, no. 5/6, p. 488, 2004.

[31] M. H. Moore, Creating public value: Strategic management in government. Cambridge, MA: Harvard University Press, 1995.

[32] K. Omar, H. Scheepers, and R. Stockdale, "eGovernment Service Quality Assessed through the Public Value Lens," in Electronic Government (M. Janssen, H. J. Scholl, M. A. Wimmer, and Y.-h. Tan, eds.), vol. 6846, pp. 431-440, Berlin, Heidelberg: Springer Berlin Heidelberg, 2011.

[33] M.-S. Pang, G. Lee, and W. H. DeLone, "IT Resources, Organizational Capabilities, and Value Creation in Public-Sector Organizations: A Public-Value Management Perspective," Journal of Information Technology, vol. 29, pp. 187-205, Sept. 2014.

[34] A. Pareja, C. Fernandez, B. Blanco, K. Theobald, and A. Martinez, Simplifying Lives: Quality and Satisfaction in Public Services. Inter-American Development Bank, 2015.

\section{Appendix}


Table 4. Component Matrix with factorial loads. The variables with factorial load above 0.4 (in absolute value) are highlighted in red

Variables

Systems make day-to-day management of the service easier.

|Existing systems ensure complete support for the service provided.

Systems are reliable in terms of availability.

Systems meet accessibility requirements.

The systems provide the data of the services in the open format.

Components

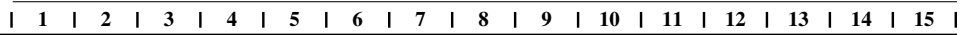
| 0.853 | $0.145|0.123| 0.131|-0.077| 0.037|-0.022| 0.016|-0.005| 0.001|0.013| 0.018|0.029| 0.054|-0.051|$ | $0.834|0.1 \quad|-0.015|0.077|-0.153|0.106|-0.051|0.065|-0.001|0.057|-0.021|0.023| 0.052|0.09|-0.028 \mid$ | $0.786|0.114| 0.216|-0.08|-0.024|0.009| 0.144|-0.01|-0.036|0.084|-0.09|-0.027|-0.118|-0.127|-0.069 \mid$ $|0.752| 0.181|0.121|-0.102|-0.05| 0.027|0.038| 0.086|-0.042| 0.043|0.026| 00.0 .156|0.047| \quad 0 \quad \mid$ | $0.64|0.044| 0.073|-0.064| 0.043|0.062| 0.265|-0.076|-0.102|0.007|-0.089|0.027|-0.003|0.085| 0.166 \mid$ $|0.457| 0.035|0.042| 0.179|0.159|-0.285|0.339|-0.217|0.012| 0.165|\quad 0 \quad| 0.128|0.092| 0.215|0.148|$ \begin{tabular}{l}
$\begin{array}{l}\text { Top management evaluates the coherence between the mission of the institution and } \\
\text { the services it offers. }\end{array}$ \\
\hline
\end{tabular} \begin{tabular}{l}
$\begin{array}{l}\text { Top management promotes improvements in management processes, with the aim } \\
\text { of reducing the requirements for service users. }\end{array}$ \\
\hline
\end{tabular} of reducing the requirements for service users.

Top management sponsors the disclosure of the services in the Services Portal. Employees are trained to provide the service as soon as they start their activities. |The institution promotes the transfer of knowledge among employees. There is a training policy for all employees.

Employees are selected from the skills required to provide the service. |The current number of employees is adequate to provide the service. Are there people specifically dedicated to quality assessment? | 0.18 | $0.79|0.195| 0.001|0.065| 0.163|0.105|-0.1|-0.004|-0.063|0.054|-0.009|0.094| 0.061|0.09|$ | $0.11|0.666| 0.238|0.141|-0.072|0.18| 0.197|0.145| 0.056|0.061|-0.009|-0.031|-0.096|0.039|-0.145 \mid$


| $0.216|0.18| 0.628|0.14| 0.175|-0.126| 0.275|0.057|-0.06|0.034| 0.069|0.103| 0.064|0.064| 0.07 \mid$

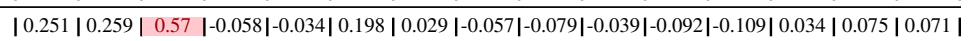
| 0.08 | 0.292 | $0.554|-0.097| 0.073|0.176|-0.004|0.001|-0.005|-0.043| 0.042|0.002| 0.245|-0.028| 0.032 \mid$ | 0.112 | $0.078|0.544| 0.024|-0.181| 0.023|0.251|-0.058|-0.03| 0.115|0.025|-0.043|-0.199|-0.201|-0.161|$ | 0.036 | $0.175|0.367|-0.063|0.041| 0.332|-0.086|-0.154|0.048| 0.192|-0.009|-0.276|0.125| 0.238|-0.165|$ \begin{tabular}{l}
$\begin{array}{l}\text { Actions that can be carried out via the internet: Step-by-step information on how to } \\
\text { order the service. }\end{array}$ \\
\hline
\end{tabular} Actions that can be carried out via the internet: Information about documents $\left.\left.\left.\left.\left.\left.\left.\left.\left.\left.\left.\left.\left.\left.\left.\right|^{-0.042}\right|^{0.081}\right|^{0.057}\right|^{0.766}\right|^{0.053}\right|^{-0.083}\right|^{-0.055}\right|^{0.093}\right|^{0.134}\right|^{-0.063}\right|^{0.017}\right|^{-0.016}\right|^{-0.067}\right|^{0.024}\right|^{-0.036} \mid$ Actions that can be carried out via the internet: Information about documents
needed to request the service.

Actions that can be carried out via the internet: Follow the service. Actions that can be carried out via the internet: Request service.

| $0.096|-0.049|-0.039|0.587| 0.205|0.086|-0.009|0.193| 0.107|0.032| 0.001|0.019|-0.046|-0.19| 0.262 \mid$ | $0.197|0.004| 0.126|0.319| 0.319|0.07|-0.045|0.188|-0.11|-0.133|-0.113|0.136|-0.13|-0.31| 0.058 \mid$ |Actions that can be carried out via the internet: Consult scheduling already done. $|-0.139| 0.003|0.015| 0.104|0.905| 0.012|000.0041| 0.029|-0.065| 0.077|-0.065| 0.01|0.077| 0.054 \mid$ |Actions that can be carried out via the internet: Perform scheduling. $\quad|-0.093| 0.049|-0.005| 0.04|0.902|-0.024|-0.035| 0.067|-0.062|-0.071|0.031|-0.035|0.045| 0.089|-0.029|$


\begin{tabular}{l}
\hline $\begin{array}{l}\text { Does the institution have a regular process of evaluating the quality of the service } \\
\text { provided? }\end{array}$ \\
\hline
\end{tabular} provided?

|Are there measurements of the user's waiting time until service delivery? $\quad|0.057|-0.067|0.066| 0.28|0.03| 0.437|0.191| 0.114|0.096| 0.009|0.176| 0.221|-0.106|-0.035|0.314|$ |Does your institution use complaint data and suggestions for service improvement? $0.209|0.113| 0.119|0.255|-0.022|0.342| 0.073|0.303|-0.054|0.097| 0.007|0.276| 0.055|0.26| 0.211 \mid$ |Regular strategies for service dissemination to the user are effective. $\quad|0.286| 0.293|0.193| 0.037|0.022| 0.019|0.624| 0.109|-0.064| 0.006|-0.02| 0.036|0.035|-0.02|-0.049|$ |Are users involved in service improvement processes? $\quad|0.041| 0.124|0.148|-0.029|-0.152| 0.271|0.591| 0.017|0.036|-0.105|0.004| 0.133|0.107|-0.012|0.087|$ \begin{tabular}{l}
$\begin{array}{l}\text { The institution is proactive in providing information of interest to users about the } \\
\text { services. }\end{array}$ \\
\hline
\end{tabular} |Channel for complaints/suggestions: Institution's own portal.

| 0.107 | $0.129|0.008|-0.018|0.112| 0.217|0.388| 0.191|0.063| 0.232|0.293|-0.354|-0.213|-0.043|-0.114|$ |Actions that can be carried out via the internet: Record suggestion / complaint. $\quad|0.021|-0.063|0.03| 0.06|0.049|-0.029|0.014| 0.833|-0.015| 0.056|0.09| 0.046|0.126| 0.094|0.028|$ \begin{tabular}{l}
$\begin{array}{l}\text { Actions that can be carried out via the internet: Receive response or solution to a } \\
\text { request, suggestion / complaint. }\end{array}$ \\
\hline
\end{tabular} The documentary requirements necessary for the provision of the service could be $\left.\left.\left.\left.\left.\left.\left.\left.\left.\left.\left.\left.\left.\left.\left.\right|^{-0.168}\right|^{-0.017}\right|^{-0.06}\right|^{0.01}\right|^{-0.115}\right|^{-0.053}\right|^{0.005}\right|^{-0.079}\right|^{0.755}\right|^{0.028}\right|^{-0.02}\right|^{0.074}\right|^{0.213}\right|^{-0.069}\right|^{0.001} \mid$
reduced. \begin{tabular}{ll|l|l|l|l|}
$\mid$ How many documents does the user need to present for the service? & $|-0.03|-0.054|-0.032| 0.335|-0.03| 0.004|-0.068|-0.064|0.624|-0.275|0.012| 0.162|-0.161| 0.068|0.021|$
\end{tabular} Actions that can be carried out via the internet: Make payment. How many areas of the institution are involved in providing the service? | $0.044|0.039|-0.141|0.12| 0.244|0.091| 0.047|0.084| 0.539|0.027|-0.131|-0.179|-0.312|-0.043| 0.067 \mid$

$|-0.165|-0.004|-0.096|-0.081|0.077|-0.002|0.019|-0.053|0.056|-0.785|0.058|-0.027|0.007| 0.008|0.018|$


Is there a total cost measurement for the user?

|Channel for complaints/suggestions: In Person (Ombudsman's Office).

|Channel for complaints/suggestions: Service Portal (servicos.gov.br).

|Channel for complaints/suggestions: Face-to-face (another service area).

Channel for complaints/suggestions: Ombudsman (e-Ouv).

|Channel for complaints/suggestions: Telephone (call center).

$\begin{array}{lllll}|0.025| 0.008|0.123| & 0 & |-0.095| 0.162|0.04| 0.053|0.07| 0.394|0.088| 0.04|-0.348| 0.002|0.321|\end{array}$

|-0.129|-0.046|0.057| $0.061|0.001|-0.032|-0.01|-0.045|-0.11|-0.124|0.771| 0.05|-0.044|-0.005|0.068|$

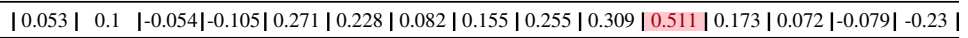

$|-0.071| 0.103|-0.039|-0.093|0.099|-0.245|\quad 0 \quad| 0.052|-0.033|-0.316|0.429|-0.394|0.163| 0.13|0.116|$

| $0.03|0.146|-0.109|0.019|-0.034|0.045| 0.144|0.008| 0.12|0.07| 0.102|0.758|-0.019|-0.001|-0.047 \mid$

$\left.\left.\left.\left.\left.\left.\left.\left.\left.\left.\left.\left.\left.\left.\left.\begin{aligned} & \text { Are there alliances, partnerships, initiatives for collaboration and / or integration } \\ & \text { with other public institutions that aim to improve the service provided? }\end{aligned}\right|^{0.149}\right|^{0.063}\right|^{0.004}\right|^{-0.077}\right|^{0.074}\right|^{0.023}\right|^{0.105}\right|^{0.179}\right|^{0.062}\right|^{-0.078}\right|^{-0.004}\right|^{-0.058}\right|^{0.743}\right|^{-0.082}\right|^{-0.009} \mid$



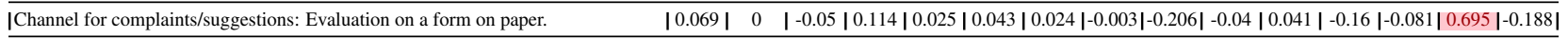
$\left.\left.\left.\left.\left.\left.\left.\left.\left.\left.\left.\left.\left.\left.\begin{aligned} & \begin{array}{l}\text { Are incentives offered to employees for their performance associated with improved } \\ \text { service quality? }\end{array} \\ & 0.15\end{aligned}\right|^{0.044}\right|^{0.039}\right|^{-0.009}\right|^{0.162}\right|^{-0.034}\right|^{-0.057}\right|^{0.029}\right|^{0.132}\right|^{-0.046}\right|^{-0.067}\right|^{0.139}\right|^{-0.018}\right|^{0.55}\right|^{0.199} \mid{ }^{-0.03}$ Is the service included in the strategic plan of the institution? Are there training actions associated specifically with the analyzed service? |Channel for complaints/suggestions: Chat or Chatbot.

|Channel for complaints/suggestions: Mobile app.

$|-0.007| 0.227|0.033|-0.004|0.031| 0.037|0.027| 0.098|0.013|-0.036|0.03|-0.078|0.004| 0.005|0.713|$ $|-0.122| 0.076|0.167| 0.001|0.063| 0.079|0.159|-0.005|0.042| 0.029|-0.129| 0.088|0.079| 0.164|0.091|$ | $0.03|-0.049|-0.063|0.214|-0.09|-0.053|-0.1|-0.112|-0.05|0.184| 0.307|-0.042| 0.122|-0.252| 0.012 \mid$ $\mathbf{|}-0.059|0.057| 0.198|-0.305| 0.008|0.067| 0.022|0.085| 0.114|0.122| 0.193|0.032| 0.132|0.07| 0.084 \mid$ $\left.\left.\left.\left.\left.\left.\left.\left.\left.\left.\left.\left.\left.\left.\begin{aligned} & \text { Does the institution follow a quality management model defined for the provision } \\ & \text { of the }-0.082\end{aligned}\right|^{0.165}\right|^{0.183}\right|^{0.004}\right|^{0.109}\right|^{0.173}\right|^{0.072}\right|^{-0.02}\right|^{0.165}\right|^{0.111}\right|^{-0.024}\right|^{-0.167}\right|^{0.137}\right|^{0.106}\right|^{0.144} \mid$



